\title{
EFEKTIVITAS MODEL PEMBELAJARAN CONTEXTUAL TEACHING AND LEARNING (CTL) DAN BERBASIS E-LEARNING EDMODO \\ TERHADAP HASIL BELAJAR SISWA PADA MATERI LANGKAH PENELITIAN GEOGRAFI DI KELAS X IPS SMA DAN MA ASSALAAM SUKOHARJO
}

\author{
Erna Mardliyana ${ }^{1}$, Chatarina Muryani ${ }^{2}$, Sarwono ${ }^{3}$ \\ 1,2,3 Program Studi Pendidikan Kependudukan dan Lingkungan Hidup (PKLH) \\ Universitas Sebelas Maret \\ Email: ernamardliyana2@gmail.com
}

\begin{abstract}
The purpose of this research is to know: (1) the difference of geography learning outcomes between using Contextual Teaching and Learning (CTL), Edmodo based on e-learning, and conventional learning model (2) the difference of geography learning outcomes between using Contextual Teaching and Learning (CTL) learning model and Edmodo based on e-learning model; (3) the difference of geography learning outcomes between using Contextual Teaching and Learning (CTL) learning model and conventional learning model; (4) the difference of geography learning outcomes between using Edmodo based on e-learning and conventional learning model on geography research step at X IPS SMA and MA Assalaam Sukoharjo. The technique ofcollecting data uses written tests in the form of multiple choice questions. The data validity uses the validity of the questionsto measure the difference, level of difficult, and reability. For the normality testing uses liliefors method, meanwhile the data analysis uses one way anava. The results of this research are: (1) There is a significant difference of geography learning outcomes between using Contextual Teaching and Learning (CTL) learning model, e-learning based on edmodo and conventional learning model; (2) There is not difference in geography learning outcomes between using Contextual Teaching and Learning (CTL) learning model and e-learning model of edmodo(both of models are equally effective); (3) the result of geography study using Contextual Teaching and Learning (CTL) learning model is better than conventional learning model; (4) the result of geography study using e-learning model of edmodo is better than conventional learning model on the research step of geography at class X IPS SMA and MA Assalaam Sukoharjo.
\end{abstract}

Keywords: CTL Learning Model, Edmodo Based E-learning, Geography Learning Outcomes of Geography Material.

\section{PENDAHULUAN}

Dunia pendidikan adalah dunia yang sangat penting dalam kehidupan manusia. Pendidikan merupakan salah satu faktor penentu kelestarian dan kemajuan bangsa, karena dengan pendidikan akan dihasilkan manusia - manusia yang berkualitas. Melalui pendidikan, generasi muda disuatu negara dapat membawa perubahan ke arah yang lebih baik.

Kualitas pendidikan dapat terlihat pada indikator keberhasilan dalam pembelajaran yaitu tercapainya tujuan pembelajaran yang ditetapkan. Salah satunya adalah dengan meningkatkan pemahaman siswa terhadap materi yang diajarkan yang dapat ditunjukkan dengan hasil belajar siswa. Selain itu pembaharuan dalam bidang pendidikan adalah pembaharuan metode. Metode dikatakan relevan jika mampu menghantarkan siswa mencapai tujuan pendidikan melalui pengajaran. Bermacam-macam metode pembelajaran yang dapat menarik minat dan motivasi siswa harus dikuasai oleh guru. Guru 
harus memperbaiki cara mengajar dan menyesuaikan metode mengajar dengan tuntunan situasi dalam melaksanakan tugas sehari-hari. Pemilihan metode, materi dan strategi pembelajaran harus disesuaikan dengan kebutuhan siswa.

Pembelajaran geografi di sekolah menengah atas saat ini masih didominasi oleh pandangan bahwa pengetahuan sebagai perangkat fakta-fakta yang harus dihafal. Guru sebagai penyaji, siswa sebagai penerima saja dan metode pembelajaran ceramah masih menjadi pilihan utama sebagai strategi belajar sehingga menyebabkan siswa menjadi jenuh dan berdampak pada menurunnya kemampuan menyerap materi pelajaran. Chickering and Gamson (1999) menyarankan agar pendidik menggunakan strategi pembelajaran aktif, agar siswa tidak hanya sekedar mendengarkan pelajaran saja.

Seorang guru yang baik sebaiknya mampu menciptakan suasana dan kondisi belajar yang merangsang minat siswa serta memenuhi kebutuhan siswa dalam mengembangkan potensinya. Guru sebaiknya juga harus memiliki strategi, agar siswa dapat belajar secara efektif dan efisien, mengena pada tujuan yang akan dicapai. Salah satu langkah untuk memiliki strategi tersebut adalah guru harus mempunyai kemampuan dalam memilih sekaligus menggunakan metode pembelajaran yang tepat dan efektif sebagai sarana interaksi guru dengan siswa dalam kegiatan belajar mengajar. Penggunaan metode yang tepat akan berpengaruh terhadap kesadaran peserta didik untuk nempelajari serta mencari informasi lebih banyak lagi karena didorong oleh kebutuhan dan rasa ingin tahu yang besar sehingga diharapkan dapat semakin mengoptimalkan potensi yang dimiliki masing-masing siswa. Guru tidak akan lagi menjadi pusat belajar, melainkan berperan sebagai fasilitator dimana siswadiberi kan kesempatan yang luas untuk berkreasi dalam menangkap materi.

Model pembelajaran yang akan digunakan untuk penelitian ini adalah model pembelajaran Contextual Teaching and Learning (CTL), pembelajaran dengan $E$ learning berbasis Edmodo, dan ceramah. Di SMA dan MA Assalaam khususnya kelas X IPS belum pernah diadakan penelitian dengan menggunakan Contextual Teaching and Learning (CTL) dan model pembelajaran $E$ learning berbasis Edmodo yang akan dibandingkan dengan model yang sering digunakan oleh guru di SMA dan MA Assalaam yaitu pembelajaran dengan model Ceramah.

Model pembelajaran Contextual Teaching and Learning (CTL) merupakan suatu proses pembelajaran holistik yang bertujuan untuk membelajarkan peserta didik dalam memahami bahan ajar secara bermakna (meaningfull) yang dikaitkan dengan konteks kehidupan nyata baik berkaitan dengan 
lingkungan pribadi, agama, sosial, ekonomi, kultural, dan sebagainya, sehingga peserta didik memperoleh ilmu pengetahuan dan keterampilan yang dapat diaplikasikan dan ditransfer dari konteks permasalahan yang satu ke permasalahan lainnya (Suhana, 2014: 67). Menurut Elaine (2014: 58) CTL adalah sebuah sistem yang merangsang otak untuk mneyusun pola-pola yang mewujudkan makna yang mana sangat cocok dengan otak yang menghasilkan makna dengan menghubungkan muatan akademik dengan konteks dari kehidupan sehari-hari siswa. Susan (2003) mengemukakan, "Contextual teaching and Leaning (CTL) is a concept that helps teachers relate subject matter to real world situations. CTL motivates learners to take charge of their own learning and to make connections between knowledge and its applications to the various contexts of their lives: as family members, as citizens, and as workers". Berdasarkan uraian tersebut, Contextual Teaching and Learning adalah sebuah konsep yang membantu guru yang menghubungkan antara materi pelajaran dengan kehidupan nyata. CTL memotivasi siswa untuk menguasai pembelajaran mereka dan menghubungkan antara pengetahuan dan penerapannya dalam kehidupannya. Contohnya: anggota keluarga, masyarakat, dan individu.

Hudson \& Whisler mengemukakan, "Contextual teaching and learning (CTL) is defined as a way to introduce content using a variety of active-learning techniques designed to help students connect what they already know to what they are expected to learn, and to construct new knowledge from the analysis and synthesis of this learning process". Berdasarkan uraian tersebut CTL merupakan gambaran sebuah cara untuk mengenalkan materi menggunakan teknik pembelajaran aktif dengan berbagai variasi yang dibuat untuk membantu siswa menghubungkan apa yang telah mereka ketahui dengan apa yang mereka harapkan dalam pelajaran, dan untuk membentuk ilmu pengetahuan baru dari analisis hasil proses pembelajaran.

$$
\text { Edmodo sebagaimana yang }
$$
diungkapkan oleh Casey Stroud dalam White Paper-nya (2010: 2) edmodo adalah jejaring sosial yang penggunaanya dikhususkan bagi dunia pendidikan. Edmodo merupakan aplikasi jaringan sosial yang memiliki tampilan yang hampir sama dengan jejaring sosial facebook, akan tetapi edmodo menciptakan lingkungan belajar online bagi siswa untuk sharing diskusi terkait materi pembelajaran untuk mencapai tujuan pembelajaran, sedangkan facebook tidak demikian halnya dengan edmodo.

$$
\text { E-learning berbasis edmodo, } e \text { - }
$$
learning sendiri adalah sistem pembelajaran yang memanfaatkan media elektronik sebagai alat untuk membantu kegiatan pembelajaran. Sebagian besar berasumsi bahwa elektronik 
yang dimaksud adalah penggunaan teknologi komputer dan internet. Melalui komputer, siswa dapat belajar secara individual baik secara terprogram maupun tidak terprogram. Sedangkan Edmodo sama seperti media pembelajaran lainnya, bisa menjadi sebuah platform online untuk mendorong pembelajaran yang dilaksanakan oleh guru, atau dapat juga menjadi cara yang lebih kreatif dalam melibatkan siswa dalam pembelajaran yang menekankan pada aspek kolaboratif. Karena edmodo memberikan arah dan jalan untuk membangun komunikasi untuk melakukan interaksi antara siswa dengan siswa dan guru dengan siswa. SEAMOLEC (2013:62) mengemukakan bahwa edmodo memiliki peranan dalam menyediakan lingkungan belajar mengajar yang dapat memberikan kesenangan bagi siswa, siswa lebih mandiri, dengan tanpa melupakan standar pengukuran keberhasilan siswa.

Sedangkan Cauley (2013) dalam Monalisa \& Ardi (2013: 221) mengemukakan edmodo adalah sebuah website pendidikan yang digunakan untuk mengambil ide-ide dari jarimgan sosial dan kemudian ide tersebut disaring agar menjadi lebih baik dan lebih santun ketika akan disajikan dalam kelas.

Pembelajaran ceramah merupakan bagian dari pembelajaran konvensional yang sama artinya dengan tradisional. Menurut Dimyati dan Mudjiono (2009: 77) "metode pembelajaran konvensional adalah suatu metode mengajar yang telah lama dan biasa digunakan oleh guru, misalnya dengan metode ceramah". dengan model pembelajaran ceramah ini tidak menutup kemungkinan anak akan menjadi jenuh dan bosan karena tidak ada variasi dalam kegiatan pembelajaran.

Penerapan model pembelajaran Contextual Teaching and Learning (CTL) dan pembelajaran berbasis e-learning edmodo sesuai dengan karakteristik pada materi langkah penelitian geografi karena dengan metode ini memungkinkan peserta didik aktif dalam pembelajaran, meningkatkan kemandirian peserta didik serta membuat peserta didik lebih bertanggung jawab saat proses pembelajaran.

Pembelajaran geografi akan lebih menarik jika dalam suatu bentuk pembelajaran terdapat inovasi model pembelajaran agar dapat meningkatkan hasil belajar siswa. Untuk itu penulis mencoba mengadakan penelitian dengan judul: "Efektivitas Model Pembelajaran Contextual Teaching And Learning (CTL) dan ELearning Berbasis Edmodo Terhadap Hasil Belajar Siswa pada Materi Langkah Penelitian Geografi di Kelas X IPS SMA dan MA Assalaam Sukoharjo". Mempunyai tujuan untuk mengetahui perbedaan hasil belajar geografi yang signifikan antara yang menggunakan model pembelajaran 
Contextual Teaching and Learning (CTL) elearning berbasis edmodo dan ceramah; perbedaan hasil belajar geografi yang signifikan antara yang menggunakan model pembelajaran Contextual Teaching and Learning (CTL) dengan yang menggunakan e-learning berbasis edmodo; Perbedaan hasil belajar geografi yang signifikan antara yang menggunakan model pembelajaran Contextual Teaching and Learning (CTL) dengan yang menggunakan model pembelajaran Ceramah; perbedaan hasil belajar geografi yang signifikan antara yang menggunakan model e-learning berbasis edmodo dengan yang menggunakan model pembelajaran ceramah pada materi langkah penelitian geografi siswa kelas X IPS SMA dan MA Assalaam Sukoharjo.

\section{METODE PENELITIAN}

Dalam penelitian ini menggunakan pendekatan kuantitatif, metode yang digunakan dalam penelitian ini adalah Eksperimen Semu (Quasi experimental research) dengan memecah kelas menjadi dua yaitu kelompok eksperimen dan kelompok kontrol. Quasi experimental research adalah mengadakan kegiatan percobaan dengan memberikan perlakuan semu. Perlakuan semu yang diberikan adalah memberikan perlakuan semu. Perlakuan semu yang diberikan adalah memberikan perlakuan dengan kegiatan uji coba e-learning edmodo. Menurut Budiyono (2003: 83) “Tujuan penelitian eksperimental semu adalah untuk memperoleh informasi yang merupakan perkiraan bagi informan yang dapat diperoleh dengan eksperimen yang sebenarnya/manipulasi semua variabel yang relevan".

Jenis desain eksperimen yang digunakan adalah desain pretest-posttest kelompok kontrol tanpa acak. Desain tersebut termasuk dalam desain eksperimen semu, yaitu desain eksperimen yang tidak memungkinkan melakukan penempatan subyek secara acak, baik karena kelompok kontrol atau komparasi tidak ada, tidak memuaskan atau mahal. Dengan demikian dalam desain ini peneliti memilih dua atau lebih kelompok subyek yang sudah ada kemudian memberikan perlakuan eksperimental. Eksperimen dilakukan di suatu kelas tertentu dengan siswa yang telah ada atau sebagaimana adanya. Peneliti tidak mungkin mengubah kelas siswa dalam menentukan subyek untuk kelompok kelompok eksperimen. Peneliti memilih dua atau lebih kelompok subyek yang sudah ada kemudian memberikan perlakuan eksperimenal. Sampel penelitian ini terbagi menjadi tiga kelompok, yaitu dua kelas eksperimen dan satu kelas kontrol. Dalam penelitian ini kelas eksperimen diterapkan metode CTL, pembelajaran berbasis edmodo. Sedangkan kelompok kontrol pada penelitian ini diterapkan metode pembelajaran ceramah.

Siswa pada awal kegiatan penelitian diberikan testawal (pretest) untuk mengetahui 
kemampuan awal siswa. Kemudian siswa diberi perlakuan dengan menggunakan model Contextual Teaching and learning (CTL) untuk kelompok 1, sedangkan kelompok 2 menggunakan e-learning berbasis edmodo. Kelompok kontrol menggunakan metode ceramah. Pada akhir penelitian, siswa dikenakan tes akhir (posttest). Hasil kedua tes tersebut dipakai sebagai data penelitian untuk kemudian diolah dan dibandingkan hasilnya dengan analisis statistik.

Subjek penelitian ini adalah siswa kelas $\mathrm{X}$ IPS SMA dan MA Assalaam Sukoharjo Tahun ajaran 2016/2017. Data diperoleh dengan menggunakan instrumen tes.

\section{HASIL PENELITIAN DAN PEMBAHASAN}

Teknik analisis data yang digunakan dalam penelitian ini adalah analisis variansi satu jalan. Dengan demikian mensyaratkan terpenuhinya dua asumsi yaitu uji normalitas dan homogenitas varian.

\section{Uji Normalitas}

Ujinormalitas nilai hasil belajargeografi materi langkah penelitian geografi mencakup hasil belajar dari: 1) kelompok siswa dengan perlakuan model Contextual Teaching and Learning (CTL); 2) kelompok siswa dengan perlakuan model e-learning berbasis edmodo; 3) kelompok siswa dengan perlakuan model pembelajaran ceramah.
Tabel 1. Rangkuman Uji Normalitas Data

\begin{tabular}{lllll}
\hline Data & Kelas & Lhitung & $\mathrm{L}_{\text {table }}$ & Kesimpulan \\
\hline Pre-Test & CTL & 0,147 & 0,180 & Normal \\
\cline { 2 - 5 } & Edmodo & 0,163 & 0,184 & Normal \\
\cline { 2 - 5 } & Ceramah & 0,136 & 0,159 & Normal \\
\hline Post- & CTL & 0,167 & 0,180 & Normal \\
Test & Edmodo & 0,178 & 0,184 & Normal \\
(Hasil & Ceramah & 0,151 & 0,159 & Normal \\
Belajar) & & & &
\end{tabular}

Penentuan normalitas dapat dilihat dari cara membandingkan $\mathrm{L}_{\text {hitung }}$ dengan $\mathrm{L}_{\text {tabel. }}$ Jika $\mathrm{L}_{\text {hitung }}<\mathrm{L}_{\text {tabel }}$ maka data tersebut berdistribusi normal. Namun jika $L_{h i t u n g}>L_{\text {tabel }}$ maka data tersebut tidak berdistribusi normal. Berdasarkan data pre-test dan data post-test (hasil belajar) masing-masing kelas berdistribusi normal. Hal tersebut dapat

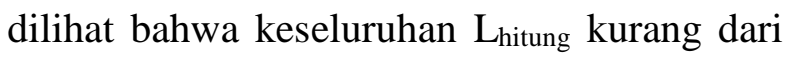
Ltabel. Dengan demikian H0 diterima dan dapat disimpulkan bahwa sampel yang terdiridari kelas Contextual Teaching and Learning (CTL), E-learning berbasis Edmodo dan ceramah berasal dari populasi yang berdistribusi normal.

2. Uji Homogenitas

Uji homogenitas varian dengan model uji bartlett yang berfungsi untuk menunjukkan bahwa populasi-populasi dari sampel penelitian ini bersifat homogen atau bervariasi sama. Hasil uji homogenitas dengan Bartlet. 
Tabel 2. Rangkuman Uji Homogenitas Data

\begin{tabular}{|c|c|c|c|}
\hline Data & Kelas & $X_{\text {hit }}^{2}$ Sig Sig & Kesimpulan \\
\hline Pre-Test & $\begin{array}{l}\text { CTL, } \\
\text { Edmodo, } \\
\text { Ceramah }\end{array}$ & $0,926>0,05$ & $\mathrm{H}_{0}$ diterima \\
\hline $\begin{array}{l}\text { Post-Test } \\
\text { (Hasil } \\
\text { Belajar) }\end{array}$ & $\begin{array}{l}\text { CTL, } \\
\text { Edmodo, } \\
\text { Ceramah }\end{array}$ & $0,838>0,05$ & $\mathrm{H}_{0}$ diterima \\
\hline
\end{tabular}

Penentuan homogenitas data dilakukan dengan membaca nilai $X^{2}$ hitung (sig). Jika $X^{2}$ hitung $($ sig) $<$ alfa $(0,050)$, maka kesimpulannya data bersifat homogen. Namun jika $\mathrm{X}^{2}$ hitung $($ sig) > alfa $(0,050)$, maka kesimpulannya data bersifat tidak homogen. Berdasarkan tabel uji homogenitas diketahui bahwa nilai $\mathrm{X}^{2}$ hitung (sig) Pre-test sebesar 0,926 dan Post-test sebesar 0,838 lebih besar dibandingkan alfa $(0,050)$, sehingga kesimpulannya data berasal dari populasi yang homogen.

3. Uji Hipotesis

Penelitian ini memiliki empat hipotesis, berikut adalah hasil uji hipotesis penelitian:

\section{a. Hasil Uji Hipotesis Pertama}

Setelah dilakukan uji prasyarat analisis yakni uji normalitas dan uji homogenitas dan diketahui data berdistribusi normal dan homogen, maka selanjutnya dilakukan uji hipotesis menggunakan analisis varian (anava) satu arah. Uji anava satu arah diguanakan untuk menguji ada tidaknya perbedaan efek perlakuan terhadap variabel terikat. Rangkuman anava satu arah adalah sebagai berikut:
Tabel. 3 Rangkuman Uji Anava

\begin{tabular}{|c|c|c|c|}
\hline Model & $F_{\text {hitung }}$ & $\mathrm{F}_{\text {tabel }}$ & Keputusan \\
\hline $\begin{array}{l}\text { Ceramah, } \\
\text { CTL, } \\
\text { Edmodo }\end{array}$ & 8,428 & 3,97 & $\mathrm{H}_{0}$ ditolak \\
\hline
\end{tabular}
penerapan model pembelajaran geografi berupa model ceramah, CTL dan Edmodo terhadap hasil belajar di SMA dan MA Assalaam Sukoharjo diperoleh. $F_{\text {hit }}=8,428>$ $\mathrm{F}_{\text {tabel }}=3,97$. Dari perhitungan One-Way ANAVA menunjukkan bahwa $\mathrm{H}_{0}$ ditolak maka dapat diartikan ada pengaruh model Ceramah, CTL dan Edmodo terhadap hasil belajar di SMA dan MA Assalaam. Dari signifikasi perhitungan diperoleh nilai (sig.) untuk model 0,000 <0,05 (alfa).

Hal tersebut membuktikan hipotesis pertama bahwa ada perbedaan hasil belajar geografi yang signifikan antara yang menggunakan model pembelajaran Contextual Teaching and Learning (CTL), berbasis e-learning edmodo dan ceramah pada materi langkah penelitian geografi siswa kelas X IPS SMA dan MA Assalaam Sukoharjo.

\section{b. Hasil Uji Hipotesis Kedua}

Untuk mengetahui signifikansi perbedaan hasil belajar peserta didik yang menggunakan model pembelajaran Contextual Teaching and Learning (CTL) dan E-learning Berbasis Edmodo maka digunakan uji lanjut pasca anava. Uji lanjut pasca anava yang digunakan adalah metode Tukey. Rangkuman uji pasca 
anava dengan metode Tukey dapat dilihat pada Tabel berikut:

Tabel 4. Rangkuman Uji Tukey

\begin{tabular}{|c|c|c|c|c|}
\hline \multirow{2}{*}{ Model } & \multirow{2}{*}{ Model } & \multirow{2}{*}{ Sig. } & \multicolumn{2}{|c|}{ Keteraangan } \\
\hline & & & Sig & Kesimpulan \\
\hline \multirow{2}{*}{ Ceramah } & CTL & .000 & $<0,050$ & $\mathrm{H}_{0}$ ditolak \\
\hline & Edmodo & .048 & $<0,050$ & $\mathrm{H}_{0}$ ditolak \\
\hline \multirow{2}{*}{ CTL } & Ceramah & .000 & $<0,050$ & $\mathrm{H}_{0}$ ditolak \\
\hline & Edmodo & .221 & $>0,050$ & $\mathrm{H}_{0}$ diterima \\
\hline \multirow{2}{*}{ Edmodo } & Ceramah & .048 & $<0,050$ & $\mathrm{H}_{0}$ ditolak \\
\hline & CTL & .221 & $>0,050$ & $\mathrm{H}_{0}$ diterima \\
\hline
\end{tabular}

Tabel diatas menunjukkan rangkuman

uji Tukey. Untuk mengetahui apakah hipotesis kedua diterima atau ditolak, maka dapat dilihat pada $F_{\text {hitung }}$ dan $F_{\text {tabel }}$ yang menunjukkan Model Contextual Teaching and Learning (CTL) dan e-learning berbasis edmodo. Berdasarkan tabel tersebut, diperoleh hasil nilai signifikansi model CTL dan edmodo adalah 0,221 > 0,05 (alfa) dengan kesimpulan $\mathrm{H} 0$ diterima maka tidak terdapat perbedaan yang signifikan dengan rerata untuk model CTL adalah 80,63 sedangkan model edmodo 78,28. Berdasarkan perhitungan hasil uji Tukey, maka dapat disimpulkan bahwa kedua model baik Contextual Teaching and Learning (CTL) maupun e-learning berbasis edmodo samasama efektif.

\section{c. Hasil Uji Hipotesis Ketiga}

Tabel yang menunjukkan rangkuman uji tukey. Untuk mengetahui apakah hipotesis ketiga diterima atau ditolak maka dapat dilihat pada $F_{\text {hitung }}$ dan $F_{\text {tabel }}$ yang menunjukkan Model Contextual Teaching and Learning (CTL) dan model ceramah. Berdasarkan tabel, hasil uji lanjut Tukey pengaruh penerapan model pembelajaran berupa model Contextual Teaching and Learning (CTL) dan ceramah terhadap hasil belajar di SMA dan MA Assalaam Sukoharjo diperoleh hasil nilai signifikasi $0,048<0,05$ (alfa) sehingga terdapat perbedaan yang signifikan dengan rerata untuk model CTL adalah 78,26 sedangkan untuk model ceramah adalah 73,39. Dapat disimpulkan bahwa Hasil belajar geografi yang menggunakan model pembelajaran Contextual Teaching and Learning (CTL) lebih baik dibandingkan dengan yang menggunakan model ceramah pada materi langkah penelitian geografi siswa kelas X IPS SMA dan MA Assalaam Sukoharjo.

\section{d. Hasil Uji Hipotesis Keempat}

Melihat tabel yang menunjukkan Hasil uji lanjut Tukey, pengaruh penerapan model pembelajaran geografi berupa model Edmodo dan ceramah terhadap hasil belajar di SMA Assalaam Sukoharjo diperoleh hasil nilai signifikasi model e-learning berbasis edmodo dan model ceramah adalah $0,048<0,05$ (alfa) sehingga terdapat perbedaan yang signifikan 
antara penerapan model Edmodo dengan model ceramah, bila dilihat dari rerata penerapan model edmodo menghasilkan rerata yang lebih baik yaitu 78,28 di bandingkan dengan model ceramah dengan rerata 73,39. Maka dapat disimpulkan bahwa Hasil belajar geografi yang menggunakan model pembelajaran berbasis E-learning Edmodo lebih baik dibandingkan dengan yang menggunakan model ceramah pada materi langkah penelitian geografi siswa kelas X IPS SMA dan MA Assalaam Sukoharjo.

4. Pembahasan

tingkat efektivitas tiga model pembelajaran yang berbeda yakni Contextual Teaching and Learning (CTL), edmodo, dan ceramah terhadap hasil belajar pesertadidik kelas X IPS 1 dan 2 baik SMA maupun MA Assalaam. masing-masing kelas diberikan perlakuan sesuai dengan langkah model pembelajaran tersebut yang menghasilkan rerata hasil belajar yang berbeda. Rerata sangat dipengaruhi oleh model pembelajaran yang digunakan. Rerata hasil belajar yang dimaksud adalah rerata jumlah scor yang diperoleh oleh peserta didik. Perbandingan rerata hasil belajar peserta didik dapat dilihat pada Tabel berikut:

Tabel. 5 Rata-rata Hasil Belajar

\begin{tabular}{ccc}
\hline \multicolumn{3}{c}{ Post-Test } \\
\hline Ceramah & CTL & Edmodo \\
\hline 73,39 & 80,63 & 78,26
\end{tabular}

Berdasarkan Tabel diatas, maka dapat dibuat histogram perbandingan rerata hasil belajar peserta didik dengan masing-masing model pembelajaran pada Gambar berikut:

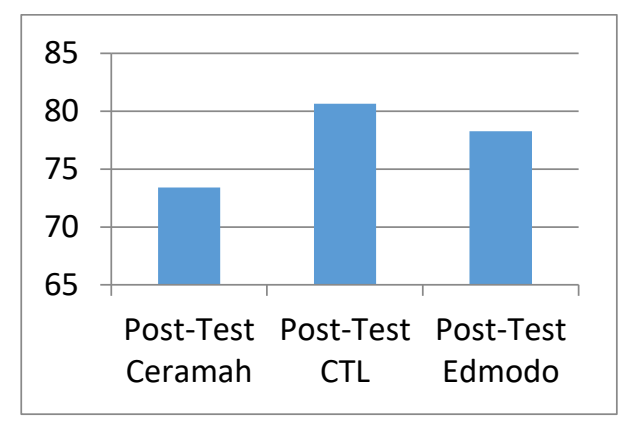

Gambar 1. Histogram Hasil Belajar

Berdasarkan histogram tersebut, diketahui bahwa perbedaan model pembelajaran menunjukkan perbedaan hasil belajar peserta didk. Rerata yang dimaksud adalah rerata skor hasil belajar peserta didik. Hal ini sesuai dengan hipotesis pertama yang menyatakan bahwa ada perbedaan hasil belajar geografi yang signifikan antara yang menggunakan model pembelajaran Contextual Teaching and Learning (CTL), berbasis e-learning edmodo dan ceramah pada materi langkah penelitian geografi siswa kelas X IPS SMA dan MA Assalaam Sukoharjo.

Pengujian hipotesis kedua dilakukan dengan menbandingkan model pembelajaran CTL dan Edmodo secara signifikan. Uji hipotesis ini menggunakan uji lanjut pasca anava dengan metode Tukey dengan taraf siginifikansi 5\%. Berdasarkan hasil uji tersebut diperoleh 0,221 >0,05 (alfa) dapat disimpulkan $\mathrm{H}_{0}$ diterima sehingga tidak 
terdapat perbedaan yang signifikan antara penerapan model CTL dan Edmodo, namun apabila dilihat dari rerata penerapan model CTL dan Edmodo menghasilkan rerata hasil belajar yang mengggunakan model CTL sebesar yaitu 80,63 lebih baik dibandingkan dengan model edmodo dengan rerata hasil belajar 78,28. Hal ini sejalan dengan hipotesis kedua ya ng menyatakan Hasil belajar geografi yang menggunakan model pembelajaran Contextual Teaching and Learning (CTL) lebih baik dibandingkan dengan yang menggunakan pembelajaran berbasis edmodo pada materi langkah penelitian geografi siswa kelas X IPS SMA dan MA Assalaam Sukoharjo.

Pengujian hipotesis ketiga dilakukan dengan membandingkan rerata pada model Contextual Teaching and Learning (CTL) dan Ceramah. uji hipotesis ini menggunakan uji lanjut pasca anava dengan metode Tukey dengan taraf signifikansi 5\%. Berdasarkan hasil uji tersebut diperoleh hasil $0,000>0,05$ (alfa) maka diperoleh hasil $\mathrm{H}_{0}$ ditolak artinya terdapat perbedaan rerata antara kelas CTL dengan nilai rerata hasil belajar 80,63 dan ceramah dengan nilai rerata hasil belajar 73,39. Melihat hasil tersebut sejalan dengan hipotesis ketiga yang menyatakan hasil belajar geografi yang menggunakan model pembelajaran Contextual Teaching and Learning (CTL) lebih baik dibandingkan yang menggunakan model ceramah pada materi langkah penelitian geografi siswa kelas X IPS SMA dan MA Assalaam Sukoharjo.

Pengujian hipotesis keempat dilakukan dengan membandingkan rerata pada model Edmodo dan Ceramah. Uji hipotesis ini menggunakan uji lanjut pasca anava dengan metode Tukey dengan taraf signifikansi 5\%. Berdasarkan hasil uji tersebut diperoleh hasil $0,048<0,05$ (alfa) maka diperoleh hasil $\mathrm{H}_{0}$ ditolak artinya terdapat perbedaan rerata antara kelas Edmodo dengan nilai rerata hasil belajar 78,26 dan ceramah dengan nilai rerata hasil belajar 73,39. Melihat hasil tersebut sejalan dengan hipotesis keempat yang menyatakan hasil belajar geografi yang menggunakan model pembelajaran e-learning berbasis edmodo lebih baik dibandingkan yang menggunakan model ceramah pada materi langkah penelitian geografi siswa kelas X IPS SMA dan MA Assalaam Sukoharjo.

\section{KESIMPULAN}

Berdasarkan hasil pembahasan yang telah dijabarkan tersebut, maka dapat disimpulkan sebagai berikut:

1. Ada perbedaan hasil belajar geografi yang signifikan antara yang menggunakan model pembelajaran Contextual Teaching and Learning (CTL), e-learning berbasis edmodo dan ceramah pada materi langkah penelitian geografi siswa kelas X IPS SMA dan MA Assalaam Sukoharjo. Hal ini dapat 
ditunnjukkan dari hasil perhitungan Anava 1 arah dengan taraf signifikansi $5 \%$ diperoleh $\mathrm{F}_{\text {hitung }}>\mathrm{F}_{\text {tabel }}(8,428>$ $3,97)$.

2. Tidak terdapat perbedaan hasil belajar geografi yang menggunakan model pembelajaran Contextual Teaching and Learning (CTL) dan yang menggunakan model e-learning berbasis edmodo pada materi langkah penelitian geografi siswa kelas X IPS SMA dan MA Assalaam Sukoharjo. Hal ini dapat ditunjukkan dari hasil perhitungan uji Tukey dengan taraf siginfikansi 5\% diperoleh hasil sig 0,221 $>$ sig 0,050 (alfa). Hasil post-test menunjukkan bahwa nilai rerata kelompok Contextual Teaching and Learning (CTL) adalah 80,63 sedangkan kelompok e-learning berbasis edmodo adalah 78,28 maka dapat disimpulkan bahwa kedua model tersebut sama-sama efektif.

3. Hasil belajar geografi yang menggunakan model pembelajaran Contextual Teaching and Learning (CTL) lebih baik dibandingkan dengan yang mengguankan model ceramah pada materi langkah penelitian geografi siswa kelas X IPS SMA dan MA Assalaam Sukoharjo. Hal ini dapat ditunjukkan dari hasil perhitungan uji Tukey dengan taraf signifikansi $5 \%$ diperoleh hasil sig $0,048<0,05$ (alfa) sehingga terdapat perbedaan yang signifikan dengan rerata untuk model CTL adalah 78,26 sedangkan untuk model ceramah adalah 73,39 .

4. Hasil belajar geografi yang menggunakan model pembelajaran E-learning berbasis Edmodo lebih baik dibandingkan dengan yang menggunakan model ceramah pada materi langkah penelitian geografi siswa kelas X IPS SMA dan MA Assalaam Sukoharjo. Dari perhitungan uji Tukey dengan taraf signifikasi 5\% diperoleh hasil nilai signifikasi model CTL dan ceramah adalah $0,048<0,05 \quad$ (alfa) sehingga terdapat perbedaan yang signifikan dengan rerata untuk model konvensional adalah 73,39 sedangakan unutk model CTL adalah 78,26.

\section{DAFTAR PUSTAKA}

Arikunto, suharsimi. 2003. Dasar-Dasar Evaluasi pendidikan. Jakarta: Bumi Aksara.

Dimyati \& Mudjiono. 2009. Belajar dan Pembelajaran. Jakarta: Rhineka Cipta.

Elaine B. Johnson. 2014.Contextual Teaching and Learning (CTL). Terj.A Chaedar Alwasilah. Kaifa Learning. Bandung.

Hudson, C.C. \& whisler, V.R. Contextual Teaching and Learning for Practitioners. Volume 6 (4), 54-58. ISSN:1690-4524.

Monalisa \& Ardi, Havid. (2013). Using "edmodo" educational social network in teaching English for high school students. Journal of English language, 2, (221). 
Sears, Susan. 2003. Introduction to contextual teaching and learning. Bloomington Indiana: The Phi Delta Kappa Educational Foundation.

Sugiyono. (2013). Metode penelitian pendekatan kuantitatif, kualitatif, dan $R \& D$. Bandung: Alfabeta.

Tim Pengembang. (2013). Buku sumber simulasi digital versi September 2013. Jakarta: SEAMOLEC

Casey Stroud. (2010). A white paper. EDUC 651: connecting technology \& curriculum edmodo. Winthrop University.

A. W. Chickering and Z. F. Gamson. 1999. Development and Adaptations of the seven principles for good practice in undergraduate education. John wiley \& sons, Inc. 